\title{
Reassessing the impact of health expenditure on income growth in the face of the global sanitary crisis: the case of developing countries
}

\author{
Brahim Gaies $^{1}$ (D)
}

Received: 17 March 2021 / Accepted: 11 January 2022 / Published online: 8 February 2022

(c) The Author(s), under exclusive licence to Springer-Verlag GmbH Germany, part of Springer Nature 2022

\begin{abstract}
In response to the COVID-19 pandemic, developing countries are increasing health spending to save lives. Such a response raises questions about the economic impact of this expenditure in terms of income growth that determines the development trajectory of these countries. This paper is the first to apply dynamic linear and threshold panel data models to capture the dynamic impact of health expenditure on growth on a large sample of developing countries, while addressing endogeneity bias and taking into account different levels of human and physical capital, as well as a set of health expenditure indicators. The main results show that while public and private domestic health expenditure increase income growth, external inflows of health expenditure do not. In addition, this positive impact is enhanced by a higher level of human and physical capital, thereby demonstrating complementarity rather than substitutability between investments in health, physical and human capital.
\end{abstract}

Keywords Development economics · Health-led growth hypothesis · Dynamic threshold model · GMM

JEL Classification I15 $\cdot$ C24 $\cdot$ F36 $\cdot$ O11

\section{Introduction}

The coronavirus pandemic has swept across the globe, reshaping the international health landscape, and triggering an economic crisis deeper than anything seen since the Great Depression. It has clearly demonstrated how health and the economy are interdependent. The International Monetary Fund predicts that more than 170 countries will experience negative per capita income growth by the end of 2020 and 71 million people could fall into extreme poverty, with developing countries being the most affected. In the face of health risks, the rapid and abrupt implementation of containment measures has flattened the infection curve while allowing time to build capacity in the health sector [1]. Many developing countries have adopted this strategy and, although they have provided less budgetary support to their economies than developed and emerging countries

Brahim Gaies

gaies_brahim@yahoo.fr

1 IPAG Lab, IPAG Business School, Paris, France due to their limited resources, the share of their additional health expenditure has been higher [2]. However, most of these countries entered the coronavirus crisis in an already vulnerable position. Half of them suffered from high public debt and the majority have been affected by an exceptional combination of external shocks, namely a sharp contraction in export volumes, lower prices of exported commodities and lower capital inflows, remittances, and tourism revenues [3]. This raises the question of the economic implications of health expenditure in these countries, beyond the social and humanitarian relevance of such spending. It is relatively clear that health spending could increase in the short term as developing countries adapt to the crisis. In the medium term, tax revenues are expected to decline, and public debt is likely to increase, reducing the room for maneuver for public spending. In the long term, the question is more about the impact on economic growth and thus on the future development of these countries.

This paper aims to answer this question by providing a comprehensive study of the linear and non-linear effects of different types of health expenditure on income growth in developing countries using the most recent data 
and covering a large sample of these countries. A review of endogenous growth theory (e.g., [4-6]) reveals that the theoretical framework linking health and growth postulates that health is a form of capital that can improve the level of output in the same way as human and physical capital. The positive effect of health expenditure is therefore expected to spread particularly through improved worker productivity, as a healthy population is more likely to learn more easily and quickly and to work longer and more efficiently [7, 8]. When it comes to testing what Atilgan et al. [9] have called the "health-led growth hypothesis" with reference to the above-mentioned theoretical framework linking health and growth, numerous empirical studies have been carried out. Halıc1-Tülüce et al. [10] ${ }^{1}$ have identified 63 empirical studies in this field using different methods and data. By and large, a wide range of results emerged from this literature and not all of them necessarily support the hypothesis of healthled growth. While panel data studies focusing on developed countries-especially OECD countries-are abundant and confirm a positive link between health expenditure and income growth (e.g., [11, 12]), investigations on nonemerging developing countries are relatively rarer. According to Atilgan et al. ([9], p. 24) "[...] most of the studies in the literature investigated the HLGH [health-led growth hypothesis] for developed countries, and there are only a few studies that focused on developing and less developed world [..]". In addition, as Yang [13] has noted, these few studies produced controversy results. For example, Narayan et al. [14], Rizvi [15] and Sarpong et al. [16] confirm the positive link between health and growth for various samples of developing countries. On the contrary, the results of De Mendonça and Baca [17] and Eggoh et al. [18] refute it. To go beyond this controversy, Yang [13] tested whether the impact of health expenditure on growth depends on the level of human capital. The author found that the healthled growth hypothesis is only valid in developing countries characterized by relatively high levels of human capital and that public health spending cannot enhance growth with low levels of human capital. This implies that human capital is a condition for securing the economic benefits of health capital in developing countries. However, Yang [13] only considered public health expenditure while neglecting other health spending, which is commonly the case in existing empirical studies on the health-led growth hypothesis in developing countries, as pointed out by Halıc1-Tülüce et al. [10]. In addition, Yang [13] used the static panel threshold model developed by Hansen [19]. This model does not control for endogeneity bias that may be caused by the problem of simultaneous causality between health expenditure and

\footnotetext{
${ }^{1}$ For a detailed review of the literature on the health-growth nexus, see [10].
}

economic growth, since many studies have shown a bidirectional relationship between these two phenomena (e.g., [8]). According to Ullah et al. ([20], p.1), "endogeneity bias can lead to inconsistent estimates and incorrect inferences, which may provide misleading conclusions and inappropriate theoretical interpretations". This bias is reinforced by the problem of omission of variables in static models of income growth - such as the static panel threshold model developed by Hansen [19]. Empirical static growth models do not capture the continuous effect of the explanatory variables in the past because they do not include the lagged dependent variable on the right-hand side of the estimated economic growth equation [21, 22]. Unlike Yang [13], Halıcı-Tülüce et al. [10] study the relationship between health expenditure and income growth using a dynamic panel data methodology and the GMM estimator to control for endogeneity and omission of variables. They also consider two different types of health spending, public and private, showing a positive effect of private health expenditure and a negative effect of public expenditure. However, Halıc1-Tülüce et al. [10] did not test for a possible threshold effect of health expenditure on economic growth as shown by Yang [13] who is still the first to use static panel threshold model to examine the hypothesis of health-led growth. In addition, the sample considered by Halıc1-Tülüce et al. [10] did not include lower-middle income developing countries since it only covers high-income countries and low-income countries.

In light of the foregoing, our article contributes to the debate on the effect of health expenditure on economic growth in four important ways. First, we develop an empirical dynamic panel data model of income growth based on an augmented endogenous growth model including different health spending indicators (current health, domestic health, public health, private health, and external health), thus going one step further than previous studies that used static panel models and focused only on private and/or public health expenditure. Second, we estimate our empirical dynamic panel data model using one- and two-step system GMM estimators to deal with endogeneity bias. We therefore go beyond the existing literature which applies standard estimators such as ordinary least squares (OLS) and fixed and random effects models, bearing in mind that these standard estimators may provide inconsistent results [20] with respect to the reversal causality and omitted variable problems characterizing the health-growth relationship. Third, to examine a potential non-linear effect of health expenditure on income growth considering potential human or physical capital thresholds, we extend our analysis using a new econometric framework based on the novel non-linear threshold GMM model developed by Seo and Shin [23]. The latter extends the Hansen [19] static panel threshold model by dealing with endogeneity bias and capturing the dynamic effect of the economic growth phenomenon. To the 
best of our knowledge, this is the first study that examines the health expenditure-income growth nexus using a nonlinear dynamic specification. Finally, our study adds to the rather scarce empirical literature on the impact of health expenditure on growth in developing economies by focusing entirely on a sample of 60 of these countries (low and lower-middle income countries) covering the most recent data available from 2000 to 2017.

Our findings provide interesting recommendations for policymakers in developing countries, especially during and after the global pandemic. They contrast with the large body of empirical investigations on the health-led growth hypothesis by showing (i) that while public and private domestic health expenditure increases income growth in developing countries, foreign health spending allocated by the government fails to produce this positive economic effect despite its social and health relevance for local populations; (ii) that both private and public health expenditure improves domestic income by increasing worker productivity, supporting the idea that a healthier population is more productive; (iii) and that an improvement in human and physical capital reinforces the positive effect of public and private health expenditure on income growth, thus demonstrating complementarity rather than substitutability between different types of capital (health, physical, education).

The rest of the paper is organized as follows. Section 2 provides a literature review of recent panel studies on the HLGH in developing countries. It also outlines the shortcomings of these studies and the contributions of this paper. Section 3 presents the model. Section 4 includes the baseline estimates and their results. Section 5 contains the robustness tests and extensions of the baseline results, while Sect. 6 concludes the study and provides policy implications.

\section{Recent literature, research gaps and contribution}

\section{Recent literature}

The HLGH is primarily rooted in endogenous growth theory (e.g., [4-6]). The main idea is that healthy workers are characterized by high productivity, which allows for continuous technological progress and increased output. Since workers are expected to live longer in better health, they learn faster and more easily and provide a greater amount of productive work time. It follows from endogenous growth theory that health spending avoids the illnesses and labor costs associated with poor health, thereby reinforcing the positive effect of health on growth through the channel of technological progress. Several empirical studies have attempted to test the HLGH, although they mainly focus on the case of developed countries and rather largely neglect developing countries. As noted in the Introduction, Atilgan et al. [9] point to the lack of panel data studies on developing and less developed economies as one of the main shortcomings of the empirical literature on the HLGH. As far as we know, there have been no more than a few dozen empirical panel studies of the HLGH in developing countries over the past decade (see Table 1 below). In addition to the plurality of their approaches, sampling, and periodicity, these analyses do not reach any consensus on the effect of health spending on economic growth. While some scholars argue that health spending is one of the main drivers of economic development in developing countries, other studies question this view by pointing out that health expenditure may encourage lower savings, which is detrimental to capital accumulation and economic growth. Such expenditures could also result in excess private and public debt, increasing the risk of default and crisis. Another argument against the HLGH is the inefficient allocation of health spending in developing countries with low institutional quality, where such spending could compete with and undermine the beneficial effects of other investments in human capital, especially in education.

One of the optimistic studies of the HLGH in Africa is that of Piabuo and Tieguhong [24] who find an unambiguous positive long-run impact of health spending on GDP growth in a sample of 12 African countries between 1995 and 2015. Piabuo and Tieguhong's [24] model is based on ordinary least squares (OLS), fully modified ordinary least squares (FMOLS) and dynamic ordinary least squares (DOLS) methods. In line with these results, Sarpong et al. [16] show that health human capital is an important factor in economic development of 35 sub-Saharan African economies. The data examined by the authors cover the period 1997-2016 and were analyzed by panel Granger causality tests and the DOLS method. Using linear panel GMM, Aboubacar and $\mathrm{Xu}$ [25] arrive at similar conclusions for a sample of 36 sub-Saharan African countries over the period 1995-2014. Relying on the same econometric method and a larger sample of 75 developing countries examined from 1995 to 2014, De Mendonça and Baca [17] mitigate these results by showing that the positive effect of public spending on growth can be distorted by high levels of corruption, which is the case in several low-income countries. Rizvi [15] shows that increased public health spending leads to higher GDP growth, when public governance is of good quality. Rizvi's [15] study employs OLS and fixed-effect estimates and a sample of 20 developing countries in South Asia, East Asia, and the Pacific covering the period 1995-2017. Using a vector autoregressive (VAR) model, Erdil and Yetkiner [26] analyze a large panel of 75 countries between 1990 and 2000 to test the HLGH. The authors show that the effect of health care expenditure on economic growth depends on the level of GDP per capita of the country group, as they found that the HLGH is verified for upper middle and high-income 


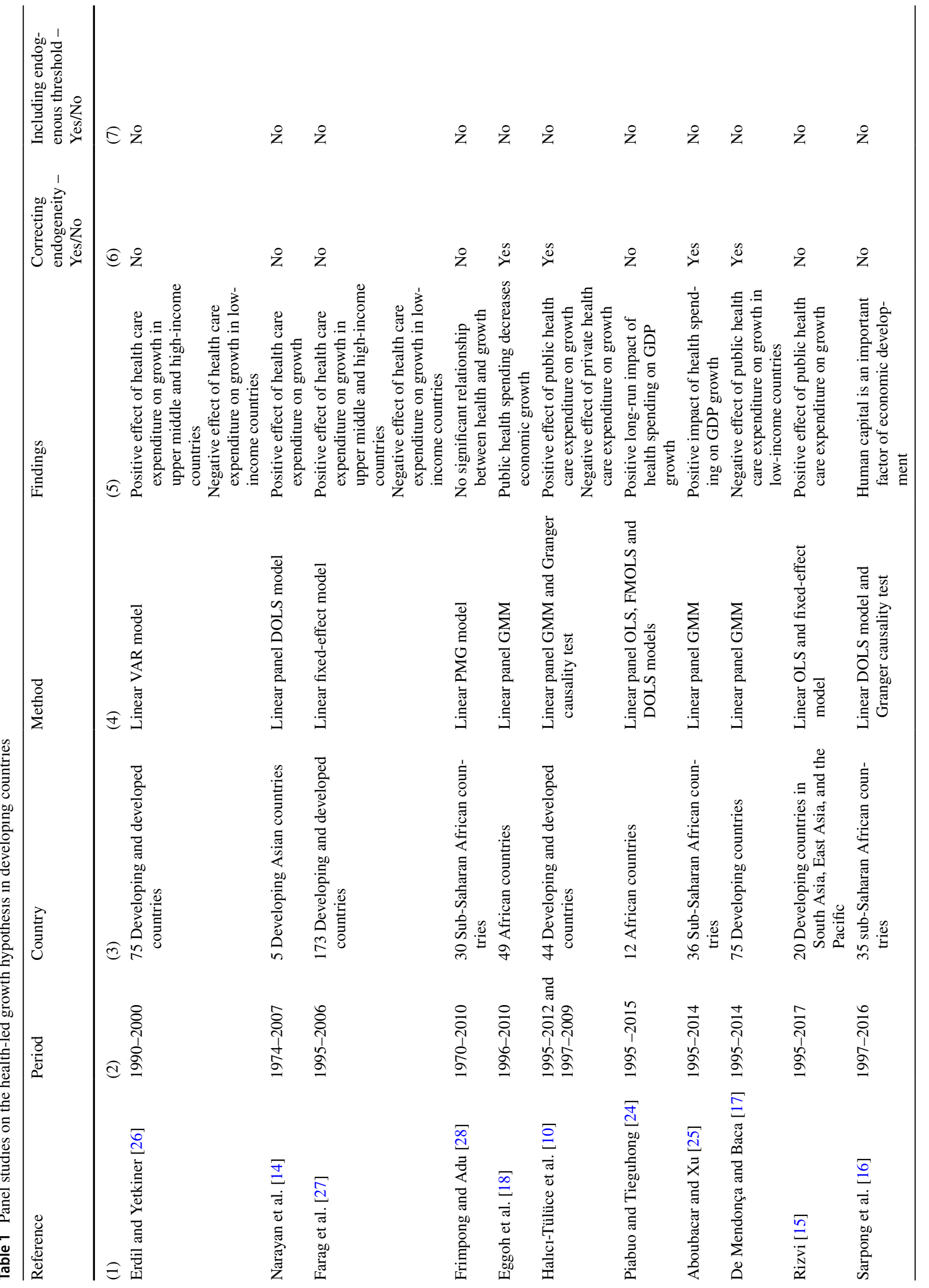


countries, while higher health care expenditure does not seem to increase economic growth in low-income countries. For a larger panel dataset of 173 countries covering the period between 1995 and 2006, Farag et al. [27] confirm the results of Erdil and Yetkiner [26] by highlighting through fixed-effect models that the relationship between health care spending and GDP growth is less consistent in low-income countries than high- and middle-income countries.

In contrast to these studies, Eggoh et al. [18] totally refute the HLGH for 49 African countries over the period 1996-2010 by showing through linear panel GMM estimates that public health spending decreases economic growth. According to the authors, high human capital is one of the necessary conditions for the HLGH to exist. The absence of this condition could lead to a negative effect of public health spending on growth. Yang [13] shows that the impact of health spending on economic growth can be negative if the national level of education is low, suggesting that human capital is a prerequisite for the HLGH to occur. The author finds that even in developing countries with a medium level of education, the effect of national health spending on growth is not significant. Only a high level of education can catalyze the positive growth effect of health expenditure. To provide this evidence, Yang [13] draws on a sample of 21 developing countries over the period 2000-2016. He is the first to apply the static panel threshold model with fixed effects (Hansen, [19]) to examine the non-linear effect of health on growth by considering education thresholds. For a sample of 5 developing Asian countries, Narayan et al. [14] show that health expenditure is one of the positive factors in GDP growth during the period 1974-2007. However, no interaction effect between human capital and health spending was shown in the study, as no significant effect of the national level of education on GDP growth was proven. The authors obtain these results employing the panel DOLS model, after analyzing the cointegration of variables in their model. No significant relationship between health and growth was found by Frimpong and Adu [28] for a sample of 30 Sub-Saharan African countries during 1970-2010. Another result shown by the study is the complementarity between education and health, as when the education variable is omitted from the model, the health variable is even less meaningful. Frimpong and Adu [28] used the pooled mean group (PMG) estimator developed by Pesaran et al. [29] to obtain these results. Finally, using the linear panel GMM and Granger causality models, Halıcı-Tülüce et al. [10] show that while public health expenditure increases GDP growth, private health expenditure decreases it. The authors explain this result by an ineffective exploitation of private health spending, infrastructure, and resources in both high-income ( 25 countries) and low-income (19 countries) economies during the periods of 1995-2012 and 1997-2009. 


\section{Research gaps and contributions}

Regarding the existing body of research reviewed above, this study contributes to the debate on the HLGH in developing countries in several ways. First, prior empirical analyses used various panel estimation methods such as OLS, FMOLS, DOLS, VAR, PMG, fixed effects, linear panel GMM, etc. to examine the impact of health expenditure on economic growth. However, only a small body of literature has examined the potential non-linear growth effects of health expenditure (see Column 4 in Table 1). This study develops a comprehensive new econometric framework based on non-linear and linear panel GMM models that explores whether there is not only monotonic but also non-monotonic relationship between health expenditure and economic growth. It is common for macro expenditure data to violate the monotonicity assumption, given the law of diminishing returns enshrined in standard economic growth theories (e.g. [4-6]). Second, a fast-growing body of recent work on the HLGH discusses the potential complementarity or substitutability between health expenditure, human capital and physical capital accumulation. However, to the best of our knowledge, only the recent study by Yang [13] examines how health expenditure affects growth by considering endogenous threshold levels of human capital. Yang ([13]; p. 175) noted that: "[...] even if there are endogenous problems, this study is still interesting as the first paper to identify the association between national health expenditures and economic growth in developing countries under different levels of human capital". We contribute to filling this gap and go one step further than Yang [13] by developing a dynamic growth model with endogenous threshold levels of both human and physical capital. Yang's [13] growth model is static and thus does not account for the continuous effect of explanatory variables in the past because it does not include the lagged dependent variable in the right-hand side of the estimated equation. It is well-known [21, 22] that static growth models can suffer from an endogenous bias due to the variable omission problem, which threatens their consistency. Our analysis is novel because it is the first to both correct for the endogeneity problem and include endogenous thresholds in a dynamic growth model (see Columns 6 and 7 in Table 1). Third, we use different indicators of health expenditures (current health, domestic health, public health, private health, and external health), thereby expanding the previous empirical literature that focuses primarily on private and/or public health expenditures. This is an interesting aspect to study, as it allows us to examine which type of health spending produces the best returns to growth, particularly in developing countries where policymakers have limited room for maneuver. Finally, our study contributes to the rather scarce empirical literature on the impact of health spending on growth in developing countries [9] by providing an analysis within less developed economies by comparing the growth effect of health spending between low-income and lower-middle income countries.

\section{The model}

We develop a dynamic panel data model of income growth, including health expenditure (health capital) based on the model of Mankiw et al. [5]. Using standard notations, the Cobb-Douglas production function is:

$Y=(K)^{\alpha}(H)^{\beta}(A L)^{1-\alpha-\beta}$.

where,

$L=L(0) e^{n t}$.

$A=L(0) e^{g t}$.

$Y$ is the output level (GDP), $K$ is the stock of physical capital, $H$ is the stock of health capital, $L$ is the labor force and A is the technology level. $\alpha+\beta<1$, and $n$ and $g$ represent the exogenous growth rates of the labor force and technology, respectively. Following Mankiw et al. [5], we assume that two constant fractions of output, namely $s_{k}$ and $s_{h}$, are invested in physical capital and health capital.

Defining physical capital per unit of labor, $k=\frac{K}{L}$, health capital per unit of labor, $h=\frac{H}{L}$, and the output level per unit of labor, $y=\frac{Y}{L}$, the accumulation of physical capital and health capital can be expressed as follows:

$\frac{\partial k}{\partial y}=s_{k} y-(n+g+\delta) k$.

$\frac{\partial h}{\partial y}=s_{h} y-(n+g+\delta) h$.

where, $\delta$ is the rate of depreciation of physical capital and health capital, since according to Mankiw et al. [5], we assume that the two capitals depreciate similarly. Following Mankiw et al. [5], the steady-state values ( ${ }^{\circ}$ ) of physical capital per unit of labor $(k)$ and health capital per unit of labor $(h)$ can be expressed as follows:

$$
\begin{aligned}
& k=\left(\frac{s_{k}^{1-\beta} s_{h}^{\beta}}{(n+g+\delta)}\right)^{1 /(1-\alpha-\beta) .} \\
& h=\left(\frac{s_{k}^{\alpha} s_{h}^{1-\alpha}}{(n+g+\delta)}\right)^{1 /(1-\alpha-\beta)},
\end{aligned}
$$


By integrating Eq. (6) and (7) into Eq. (1), and taking natural $\operatorname{logs}(\ln )$, we obtain the following equation of the steady-state output level per unit of labor:

$$
\begin{aligned}
\ln (\dot{y})= & \ln A(0)+g-\frac{\alpha+\beta}{1-\alpha-\beta} \ln (n+g+\delta) \\
& +\frac{\alpha}{1-\alpha-\beta} \ln \left(s_{k}\right)+\frac{\beta}{1-\alpha-\beta} \ln \left(s_{h}\right) .
\end{aligned}
$$

To express the variation in output levels, we use the method of Mankiw et al. [5] which linearizes the transition path around the steady-state output level $(\dot{y})$. This consists in expressing Eq. (8) in an autoregressive form considering two periods, $\left(t_{1}\right)$ and $\left(t_{p}\right)$.

$$
\begin{aligned}
\ln \left(y_{t p}\right)= & \theta \ln \left(y_{t 1}\right)+(1-\theta) \ln A(0)+g\left(_{t p_{-} t 1}\right) \\
& -(1-\theta) \frac{\alpha+\beta}{1-\alpha-\beta} \ln (n+g+\delta) \\
& +(1-\theta) \frac{\alpha}{1-\alpha-\beta} \ln \left(s_{k}\right) \\
& +(1-\theta) \frac{\beta}{1-\alpha-\beta} \ln \left(s_{h}\right),
\end{aligned}
$$

where $y_{t}=\frac{Y_{t}}{L_{t}}$ stands for the output level per unit of labor, $\theta=$ $e^{-\varphi_{1}}\left({ }_{t p_{-} t 1}\right)$ and $\varphi_{1}$ is the rate of convergence. Thus, Eq. (9) can represent a dynamic panel data model of income growth, where, according to Aghion and Howitt [6], $\ln A(0)$ stands for the time-invariant individual effect and $g\left(t_{t p_{-} t}\right)$ is the technological process over time. The latter is a function of education and economic openness, which are synonymous with progress and knowledge transfer [4]. By rewriting Eq. (9) with error terms $\left(\epsilon_{i t}\right)$ and using standard notation of panel data literature, we obtain:

$\ln \left(y_{i t}\right)=\theta \ln \left(y_{i t-1}\right)+\sum_{j=2}^{5} \varphi_{j} x_{i t}^{j}+\varphi_{0}+\epsilon_{i t}$,

where, $\ln \left(y_{i t}\right)=\ln \left(y_{t p}\right) ; \ln \left(y_{t-1}\right)=\ln \left(y_{t 1}\right) ; \theta=e^{-\varphi_{1}}{\left({ }_{t p-t 1}\right)}_{t_{-}}$; $\varphi_{2}=(1-\theta) \frac{\alpha}{1-\alpha-\beta} ; \varphi_{3}=(1-\theta) \frac{\beta}{1-\alpha-\beta} ; \varphi_{4}=-(1-\theta) \frac{{ }_{t}+\bar{\tau}+\beta}{1-\alpha-\beta} ;$ $x_{i t}^{2}=\ln \left(s_{k}\right) ; x_{i t}^{3}=\ln \left(s_{h}\right) ; x_{i t}^{4}=\ln (n) ;^{2} \quad x_{i t}^{5}=g\left(t_{t p_{-} t 1}\right)$; $\ln A(0)=\varphi_{0}+\epsilon_{i t} ;^{3}$ “ $i ”=1,2, \ldots N$ indexes countries and " $t$ " $=1,2, \ldots P$ indexes time periods.

Following Mankiw et al. [5] and Aghion and Howitt [6] among others, we approximate $x_{i t}^{4}$ by population growth

\footnotetext{
${ }^{2}$ Following Mankiw et al. [5], we assume that the rate of depreciation of physical capital and health capital $(\delta)$ is homogenous across countries and that the growth rate of technology $(g)$ varies only over time, since it is also homogenous across countries.

3 According to Mankiw et al. [5], $\ln A(0)$ includes not only technology but also resource endowments, climate, as well as political and institutional factors.
}

(Population), $x_{i t}^{2}$ by Health Expenditure (Current Health, Domestic Health, Public Health, Private Health and External health, alternatively), $x_{i t}^{3}$ by gross capital formation to GDP (Investment), and $y_{i t}$ by real GDP per capita. According to Grossman and Helpman [4] and Darku and Yeboah [30], we replace $g\left(t p_{-t 1}\right)$ by two variables, $\operatorname{School}^{4}\left(x_{i t}^{5}\right)$ and Trade $\left(x_{i t}^{6}\right)$ since we assume that the technological process is a function of education and economic openness. In addition, following this literature, we add the inflation rate (Inflation) as an indicator of economic stability $\left(x_{i t}^{7}\right)$. Finally, the extended and linear form of Eq. (10) can be expressed as follows:

$$
\begin{aligned}
\ln \left(y_{i t}\right)= & \theta \ln \left(y_{i t-1}\right)+\varphi_{0}+\varphi_{2} \text { HealthExpenditure }_{i t} \\
& +\varphi_{3} \text { Investment }_{i t}+\varphi_{4} \text { Population }_{i t}+\varphi_{5} \text { School }_{i t} \\
& +\varphi_{6} \text { Trade }_{i t}+\varphi_{7} \text { Inflation }_{i t}+\epsilon_{i t} .
\end{aligned}
$$

\section{Baseline estimations and results}

\section{Estimations}

The lag of real GDP per capita to the right of Eq. (11) captures the continuous effect of the explanatory variables in the past, which prevents the problem of omission of variables that could bias static models of income growth [20-22]. Our dynamic model thus provides a better explanation than static models that do not take into account past realizations of income growth to explain the link between income and health expenditure. However, the presence of the lagged dependent variable on the right-hand side of Eq. (11) could imply a problem of endogeneity by correlating the lag of real GDP per capita and the error terms $\left(\operatorname{cov}\left(y_{i t-1} \mid \epsilon_{i t}\right) \neq 0\right)$ since the initial income can explain the level of energy consumption, resource endowments, political and institutional factors included in the error terms, as mentioned above. In addition, the other explanatory variables may be endogenous with respect to income growth $\left(\operatorname{cov}\left(\sum_{j=2}^{7} x_{i t}^{j} \mid \epsilon_{i t}\right) \neq 0\right)$ due to the problem of simultaneous causality, especially regarding the income-health expenditure nexus. Even more so, the explanatory variables could be correlated with country-specific effects (e.g., the correlation between economic openness and geographical characteristics) incorporated in the error terms $\left(\operatorname{cov}\left(\sum_{j=2}^{7} x_{i t}^{j} \mid \sigma_{i}\right) \neq 0\right.$, where $\epsilon_{i t}=\sigma_{i}+\vartheta_{i t} ; \sigma_{i}$ represents the country-specific effects and $\vartheta_{i t}$ is an i.i.d. variable). This correlation constitutes another source of endogeneity bias.

\footnotetext{
${ }^{4}$ Following David [31], we use the school enrollment, primary and secondary (gross), gender parity index (GPI).
} 
Regarding this problem, the standard estimators ordinary least squares (OLS) and fixed and random effects produce biased results. Even estimators based on exogenous instrumental variables, such as the two- and three-stage least squares (2SLS; 3SLS) estimators, may not account for endogeneity because of the weakness of exogenous instruments. ${ }^{5}$ For these concerns, following recent empirical applications of dynamic growth models using panel data (e.g., [10, $30,33,34]$, we use the panel GMM approach to estimate Eq. (11). There are two types of panel GMM estimators, the difference GMM and the system GMM. Panel difference GMM estimations are obtained by expressing Eq. (11) in first difference and then performing the generalized method of moments [35, 36]. Using the reduced form of Eq. (11) expressed by Eq. (10) and introducing the first-difference transformation $(\Delta)$, we obtain:

$\Delta \ln \left(y_{i t}\right)=\theta \Delta \ln \left(y_{i t-1}\right)+\sum_{j=2}^{7} \varphi_{j} \Delta x_{i t}^{j}+\Delta \epsilon_{i t}$.

Implying,

$\ln \left(y_{i t}\right)-\ln \left(y_{i t-1}\right)=\theta\left(\ln \left(y_{i t-1}\right)-\left(\ln \left(y_{i t-2}\right)\right)\right.$

$+\sum_{j=2}^{7} \varphi_{j}\left(x_{i t}^{j}-x_{i t-1}^{j}\right)+\vartheta_{i t}-\vartheta_{i t-1}$,

where, $\epsilon_{i t}=\sigma_{i}+\vartheta_{i t} ; \sigma_{i}$ represents the country-specific effects and $\vartheta_{i t}$ is an i.i.d. variable.

As shown in Eq. (13) the country-specific effects and the constant have been eliminated $\left(\Delta \varphi_{0}\right.$ and $\left.\Delta \sigma_{i}=0\right)$, thus solving the potential problem of endogeneity resulting from the correlation between the explanatory variables with the country-specific effects. In the meantime, this transformation entails another problem arising from the correlation between the i.i.d. variable in difference $\left(\vartheta_{i t}-\vartheta_{i t-1}\right)$ and the lag of real GDP per capita in difference $\ln \left(y_{i t-1}\right)-\ln \left(y_{i t-2}\right)$. According to Arellano and Bond [35], to solve this problem, we consider the lag of our explanatory variables in level as instruments, assuming the absence of serial correlation $\left(\operatorname{cov}\left(\epsilon_{i t} \mid \epsilon_{i s}\right) \neq 0\right.$, where $\left.t \neq s\right)$ and that initial conditions are provided $\left(\operatorname{cov}\left(\ln \left(y_{i t}\right) \mid \epsilon_{i t}\right)=0\right.$ for $\left.t \geq 2\right)$. These assumptions imply two moment restrictions, namely $\operatorname{cov}\left(\ln \left(y_{i t-s}\right) \mid \Delta \epsilon_{i t}\right)=0$ for $\quad s \geq 2$ and $t=3, \ldots, T \quad$ and $\operatorname{cov}\left(\sum_{j=2}^{7} x_{i t-s}^{j} \mid \Delta \epsilon_{i t}\right)=0$ for $s \geq 2 \operatorname{and} t=3, \ldots, T$.

According to Arellano and Bover [36] and Blundell and Bond [37], with finite sample panel data where the individual dimension is smaller than the time dimension (which corresponds to our data), the lags of the explanatory variables in level could be weak instruments due to their meaningless correlation with their difference. To address

\footnotetext{
${ }^{5}$ For more detailed explanations, see Roodman [32], Gaies et al. [33] and Windmeijer et al. [38].
}

this concern, we perform the improved version of the panel GMM estimators, namely the system GMM developed by Arellano and Bover [36] and then Blundell and Bond [37]. Applying a system GMM consists of an estimation by the generalized method of moments of Eq. (12) expressed in difference. Then, we combine it with its expression in level as follows:

$\left\{\begin{array}{c}\Delta \ln \left(y_{i t}\right)=\theta \Delta \ln \left(y_{i t-1}\right)+\sum_{j=2}^{7} \varphi_{j} \Delta x_{i t}^{j}+\Delta \epsilon_{i t} \\ \ln \left(y_{i t}\right)=\theta \ln \left(y_{i t-1}\right)+\sum_{j=2}^{7} \varphi_{j} x_{i t}^{j}+\varphi_{0}+\epsilon_{i t}\end{array}\right.$.

To do so, we use the lags of the explanatory variables in level as instruments for the differenced equation and the explanatory variables in difference as instruments for the equation in level. We therefore obtain consistent instruments by assuming two moment restrictions, namely $\operatorname{cov}\left(\ln \Delta\left(y_{i t-1}\right) \mid\left(\sigma_{i}+\vartheta_{i t}\right)\right)=0$ for $\quad t=3, \ldots, T \quad$ a n d $o v\left(\sum_{j=2}^{7} x_{i t-1}^{j} \mid \Delta \vartheta_{i t}\right)=0$ for $t=3, \ldots, T$.

Two variants of system GMM exist, namely the one-step system GMM and the two-step system GMM. According to Roodman [32], Ullah et al. [20], Windmeijer [38] and Windmeijer et al. [39], two-step system GMM is more efficient than the one-step system GMM because it includes optimal weighting matrices. However, we use both estimators to test the robustness of our estimates and we restrict the moment conditions to a maximum of three lags to prevent the potential inefficiency due to the problem of "too many instruments". 6

Two specification tests are adopted to verify the consistency of the one- and two-step system GMM estimators [20, 32, 38, 39]. First, the serial correlation test of Arellano and Bond [35] (AR2), whose null hypothesis corresponds to the inexistence of second-order autocorrelation and therefore the validity of the instruments. Second, Hansen's test of overidentifying restrictions, whose null hypothesis corresponds to the absence of correlation of the instruments with the error term. We validate these tests for all our estimates at the $1 \%$ level.

To estimate our model, we use an unbalanced panel data set of 60 developing countries over the years 2000 to 2017. We chose this sample because previous studies on the impact of health expenditure on income growth have focused more on OECD countries than on developing countries. We were also constrained by data availability, which led us to exclude countries with too much missing data. In addition, we exclude upper-middle-income countries by referring to the World Bank's classification, thus retaining low and lower-middle-income countries to promote homogeneity in

\footnotetext{
${ }^{6}$ We generate robust one- and two-step standard errors according to the Windmeijer [38] methodology, which is detailed by Roodman [32] and Windmeijer et al. [39] using the Stata code: xtabond2.
} 
our sample. The appendix lists the sample countries, the definitions, and sources of variables (see Appendix Table 8), as well as their descriptive statistics (see Appendix Table 9) and the pooled scatterplots of the correlation between health expenditure variables and GDP per capita (Fig. 1).

\section{Results}

The empirical results of our model (Eq. (11)) using one- and two-step system GMM are presented in Table 2. They have relatively qualified the health-led growth hypothesis [9] in the case of developing countries by indicating that there is no effect of external health expenditure (inflows) on income growth, whereas the effect of domestic health expenditure is positive and significant at the $1 \%$ level. In addition, a positive effect of public health expenditure on income growth exists at the $1 \%$ and $5 \%$ levels, such that a $1 \%$ increase (decrease) in such expenditure increases (decreases) the income growth rate by $0.04-0.05 \%$. Similarly, a $1 \%$ increase (decrease) in private expenditure increases (decreases) income growth by $0.05-0.07 \%$, and overall, a $1 \%$ increase in current health expenditure increases (decreases) growth by $0.04-0.05 \%$. In summary, these results show that developing countries do not really benefit from direct foreign transfers or foreign transfers, both allocated by the government to the national health system. This can be explained by the fact that external expenditure per capita (7.18 US dollars according to Table 9 in the appendix) is very low compared to domestic expenditure per capita (60.84 US dollars according to Table 9 in the appendix). In addition, international health assistance cannot necessarily keep pace with the economic needs of recipients [40] and national governments may misallocate external health spending because of institutional weakness in developing countries.

Furthermore, as shown in Table 2, the signs of the coefficients of the control variables ${ }^{7}$ are consistent with the seminal theoretical model of endogenous growth (e.g., [4-6]) and with recent empirical applications of dynamic growth models using panel data $[10,30,39,40]$ when significant. The coefficients reveal a positive impact of education (School) - as an indicator of human capital—and physical capital investment (Investment) on income growth, while an increase (decrease) in inflation and population growth diminishes (enhances) it. The coefficient of the lagged dependent variable (Initial GDP per Capita) is positive, lower than the unit and significant at the $1 \%$ level, which shows the relevance of our dynamic specification. In the same vein, the Hausman test does not reject over-identification restrictions and, similarly, the AR2 test does not reject the absence of the

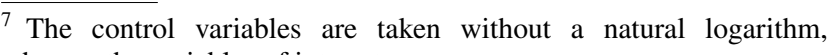
whereas the variables of interest are.
}

second-order serial correlation, which proves that our model is relatively well specified.

\section{Robustness tests and extended results}

To test the robustness of our results presented in Table 2, we split our sample of developing countries into two subgroups, low-income and lower-middle-income countries, and consider worker productivity rather than GDP per capita as the dependent variable. Subsequently, to extend these results, we use a dynamic panel threshold model with a GMM estimator to capture the potential non-linear effects of health expenditure on income growth.

\section{Sample splitting}

One of the strengths of this study is that it covers a large sample of developing countries-excluding developed and emerging countries-because according to Atilgan et al. [9], these countries have been relatively neglected in the previous literature on the impact of health expenditure on growth using panel data. However, we test whether our sample is sufficiently homogeneous to provide relatively similar results when we divide it into subgroups.

Tables 3 and 4 reported our one- and two-step system GMM estimates presented in Table 2 after splitting our main sample of 60 developing countries into two subgroups, 22 low-income and 38 lower-middle-income countries according to the Word Bank classification. As Tables 3 and 4 show, the results for the two subgroups are quantitatively similar to those shown in Table 2. They confirm that while private and public health expenditure significantly increases income growth (at the conventional levels), external health expenditure does not. Thus, our results are robust to sample splitting, proving the homogeneity of our baseline sampling.

\section{Alternative dependent variable}

Endogenous growth theory (e.g., $[5,6]$ ) postulates that healthy workers are more productive because they develop higher learning capacities and can work longer, thereby increasing the level of output. We therefore test the hypothesis that an increase in health expenditure improves the health and productivity of workers. To test this hypothesis, we also examine the robustness of the results reported in Table 2 by reconducting our one- and two-step system GMM estimates by replacing the dependent variable GDP per capita with the variable GDP per worker. The results of this test presented in Table 5 validate the hypothesis that domestic health expenditure- - both public and private-increases worker productivity. However, this effect is not significant 


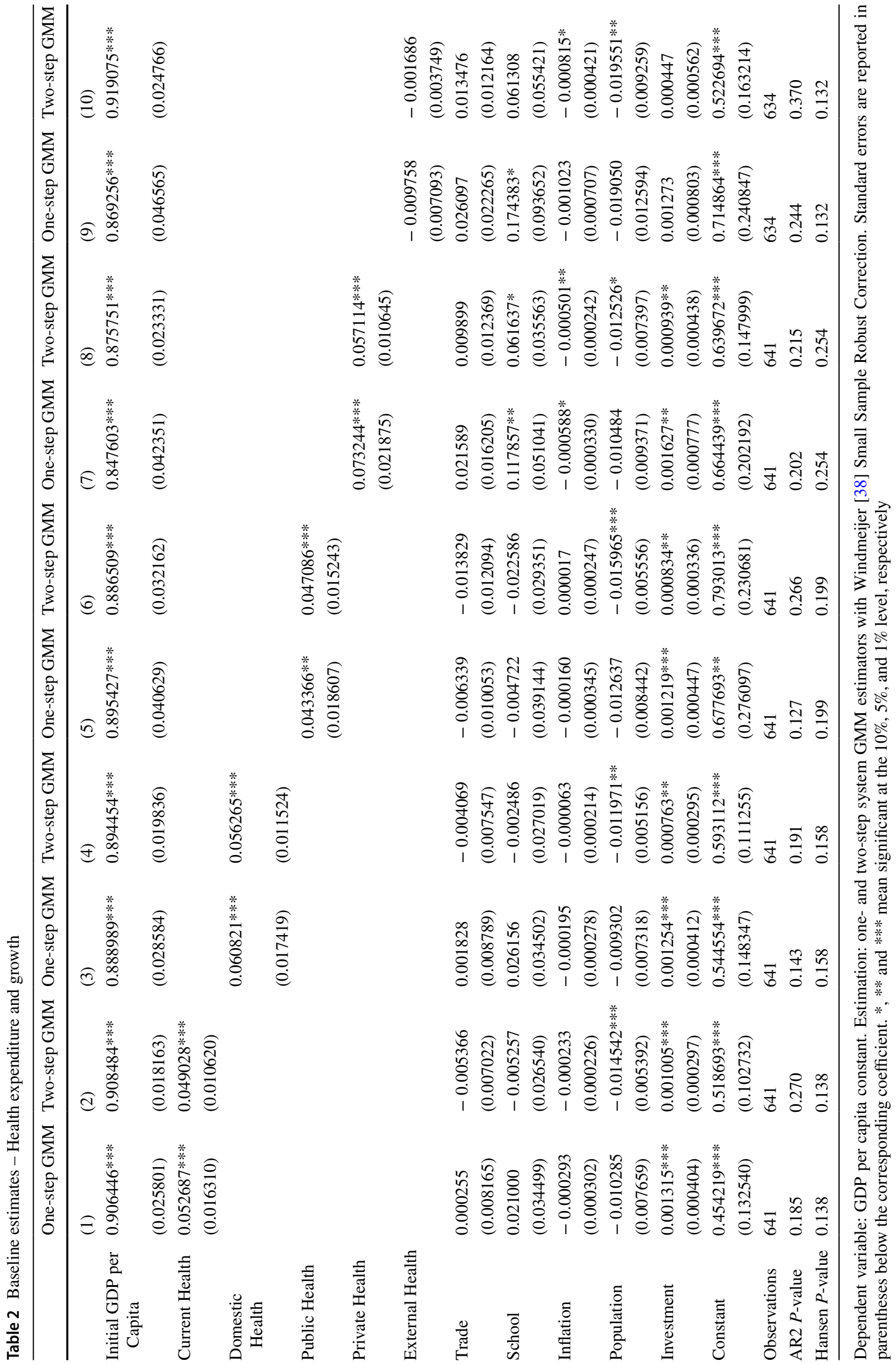


for external health expenditure. This confirms the robustness of the results reported in Table 2.

\section{Non-linear effects}

The one- and two-step system GMM estimators allow estimating the dynamic panel data model of growth since they deal with endogeneity bias by preventing the problem of omission of variables that could bias static models and the problem of reversal causality. However, both estimators do not take into account the existence of a potential threshold at which the impact of health expenditure on income growth can change. A close review of the theoretical literature on the effects of health expenditures on growth reveals that there are strong presumptions that the level of human capital, approximated by the level of education, and the level of physical capital can play this threshold role [42, 43]. To our knowledge, Yang [13] was the first study to examine the impact of health expenditure on growth by considering the level of human capital as an endogenous threshold variable. However, Yang [13] applied the static panel threshold model developed by Hansen [19] which does not deal with the endogeneity bias implying a risk of inconsistent results [20]. Also, Yang [13] only considered public health expenditure, neglecting private, external, and current expenditure. To go one step further and to extend our baseline results reported in Table 2, we use the novel dynamic panel threshold model with the one- and two-step GMM estimators. This dynamic model is developed by Seo and Shin $[23]^{8}$ extending the Hansen [19] static panel threshold model and the Kremer et al. [44] dynamic panel threshold model. It has recently started to be applied by the latest empirical applications of dynamic threshold growth models using panel data, such as Zhu et al. [45] and Osei and Kim [46].

Using the dynamic threshold GMM model, we respectively test whether there is a level of human or physical capital beyond which the impact of current, domestic, private, public, and external health expenditure on income growth becomes stronger, vanishes, or changes in nature, as expressed by the following extended forms of Eq. (11):

$$
\begin{aligned}
\ln \left(y_{i t}\right)= & \theta \ln \left(y_{i t-1}\right)+\varphi_{0} \\
& +\varphi_{2}^{L} \text { HealthExpenditure }_{i t} I\left(\text { School }_{i t}<\tilde{y}\right) \\
& +\varphi_{2}^{H} \text { HealthExpenditure }_{i t} I\left(\operatorname{School}_{i t} \geq \tilde{y}\right) \\
& +\varphi_{3} \text { Investment }_{i t}+\varphi_{4} \text { Population }_{i t} \\
& +\varphi_{5} \text { School }_{i t}+\varphi_{6} \text { Trade }_{i t}+\varphi_{7}{\text { Inf } \text { lation }_{i t}+\epsilon_{i t} .}
\end{aligned}
$$

And,

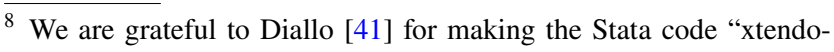
thresdpd" for this model available to the public.
}

$$
\begin{aligned}
\ln \left(y_{i t}\right)= & \theta \ln \left(y_{i t-1}\right)+\varphi_{0} \\
& +\varphi_{2}^{L} \text { HealthExpenditure } \\
& I I\left(\text { Investment }_{i t}<\tilde{y}\right) \\
& +\varphi_{2}^{H} \text { HealthExpenditure }_{i t} I\left(\text { Investment }_{i t} \geq \tilde{y}\right) \\
& +\varphi_{3} \text { Investment }_{i t}+\varphi_{4} \text { Population }_{i t}+\varphi_{5} \text { School }_{i t} \\
& +\varphi_{6} \text { Trade }_{i t}+\varphi_{7}{\text { Inf } \text { lation }_{i t}+\epsilon_{i t},}
\end{aligned}
$$

where School and Investment represent alternatively the threshold variables that divide the sample into two regimes including two different regression slope parameters, $\varphi_{2}^{L}$ (lower regime) and $\varphi_{2}^{H}$ (higher regime). $I($.) is an indicator function of the regime which is defined by the threshold variables. $\tilde{y}$ is the potential threshold value at the 5\% level. In accordance with Zhu et al. [45] and Osei and Kim [46], in addition to the serial correlation test of Arellano and Bond [35] (AR2) and the Hansen test of over-identifying restrictions, we perform the Wald linearity test ${ }_{\text {sup }} W n(\tilde{y})$, where ${ }_{\text {sup }} W n($.$) is the Wald statistic of the corresponding threshold$ value $\tilde{y}$. The null hypothesis of the Wald linearity test is $H_{0}$ : $\widehat{\varphi_{2}^{L}}=\widehat{\varphi_{2}^{H}}$.

Tables 6 and 7 present the estimates of the dynamic panel threshold model with one- and two-step GMM estimators expressed in Eq. (15) and (16). According to Tables 6 and 7 , it appears that current, domestic, public and private health expenditure increases income at lower and higher levels of education and investment. However, the magnitude and the significance of this positive effect is more pronounced in the higher education and investment regimes $\left(\varphi_{2}^{H}\right)$ than in the lower education and investment regimes $\left(\varphi_{2}^{L}\right)$. As shown in the first rows of Tables 6 and 7, the threshold levels of education and investment at which the positive effect of health spending on growth is strengthened vary according to the nature of health expenditure. Overall, the thresholds are between 1.08 and 0.66 points for the level of education ${ }^{9}$ and between $24.45 \%$ and $24.50 \%$ for the level of investment ${ }^{10}$ at the significance level of $5 \%$. Thus, an improvement in human and physical capital seems to reinforce the positive effect of health spending. This result shows complementarity rather than substitutability [42] in the accumulation of different types of capital (health, physical, education) in developing countries. Nevertheless, the impact of external health expenditure on income growth is non-significant at the conventional levels, both in lower and higher education and investment regimes.

In addition, Tables 6 and 7 show that, when significant, the coefficients of the control variables have the same signs as those of the baseline estimates reported in Table 2, which

\footnotetext{
${ }^{9}$ When the index is less than 1 , it means that girls are more disadvantaged than boys in terms of schooling.

${ }^{10}$ Investment (gross capital formation) is expressed as a percentage of GDP.
} 


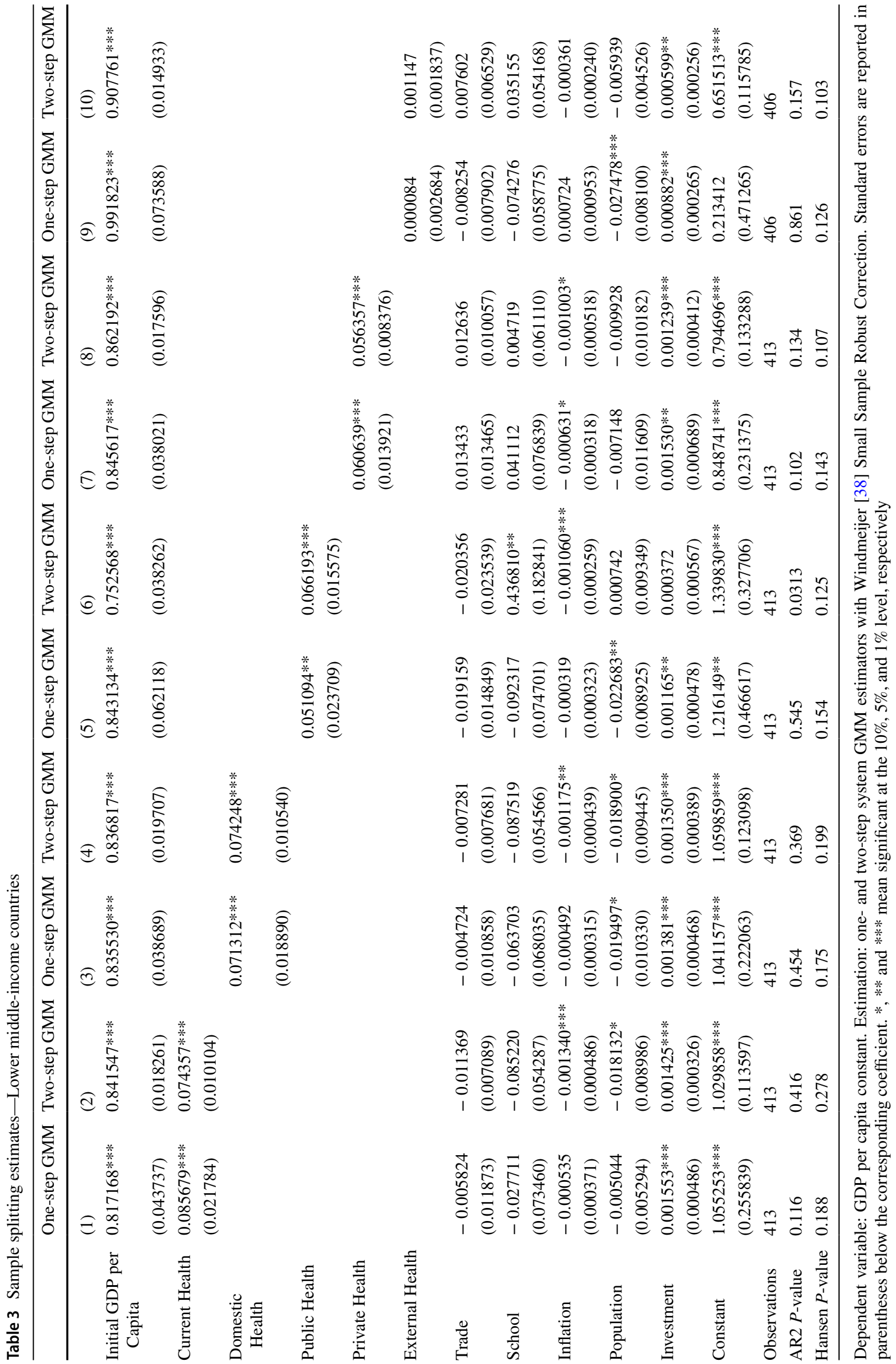




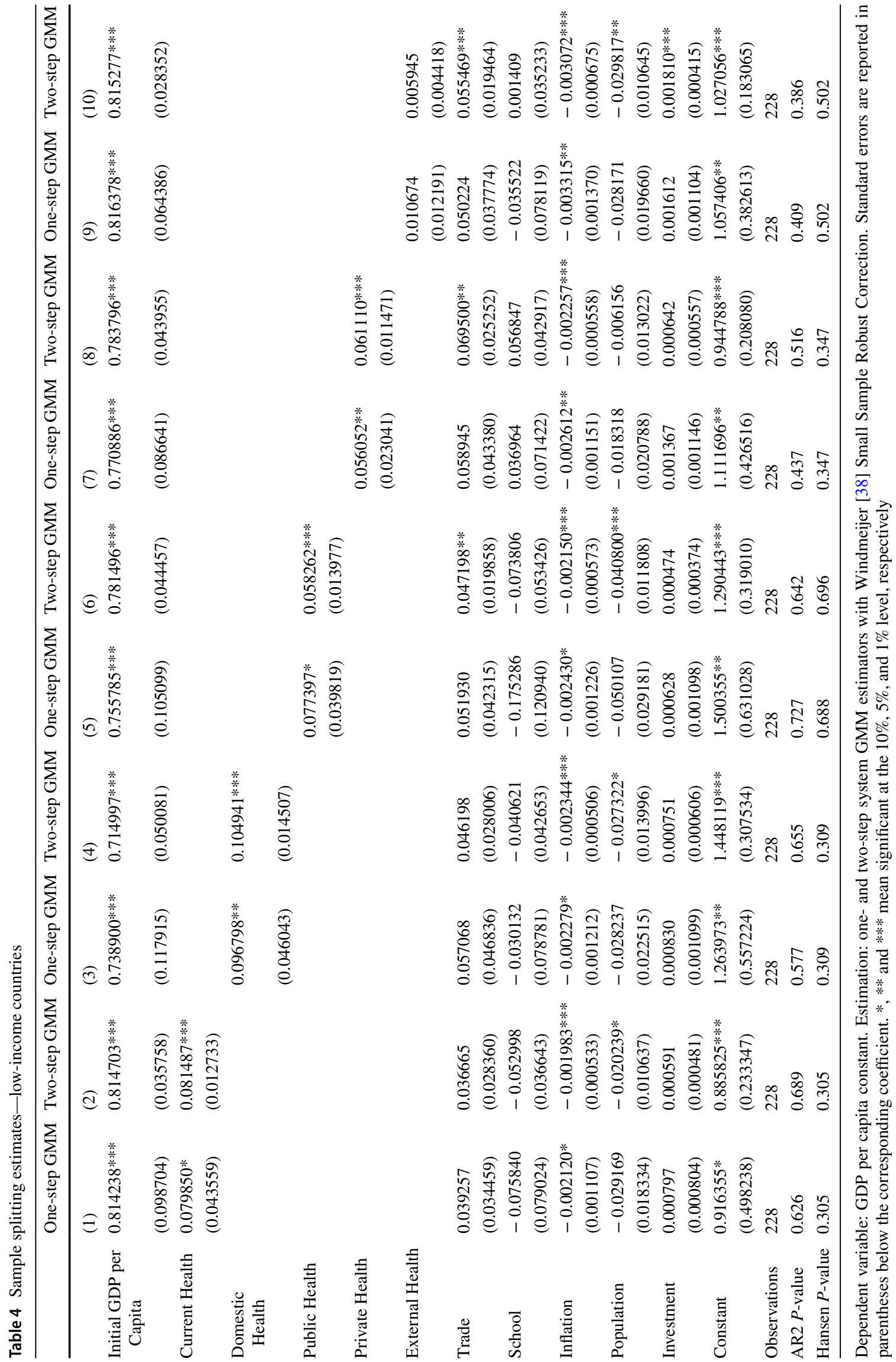




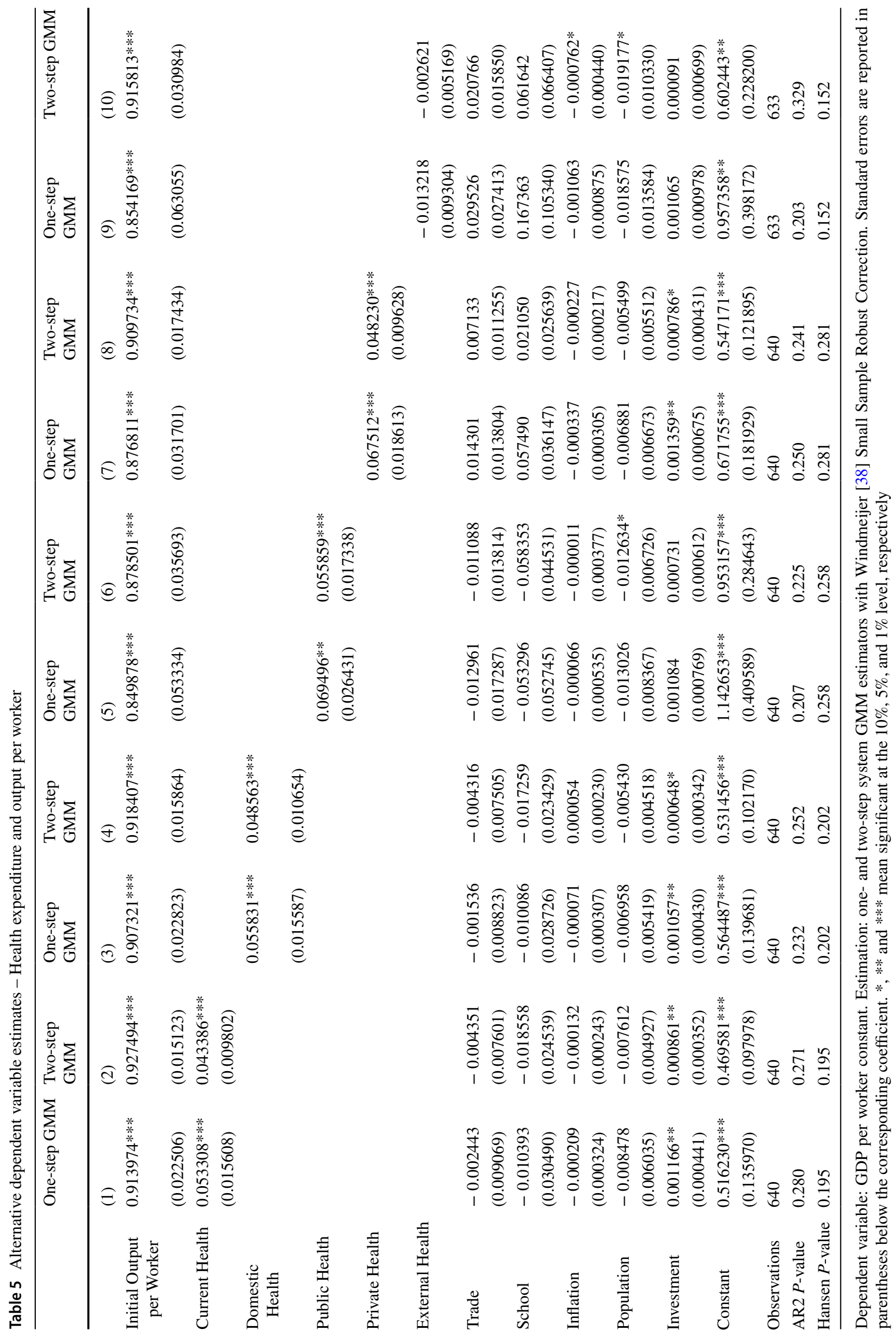




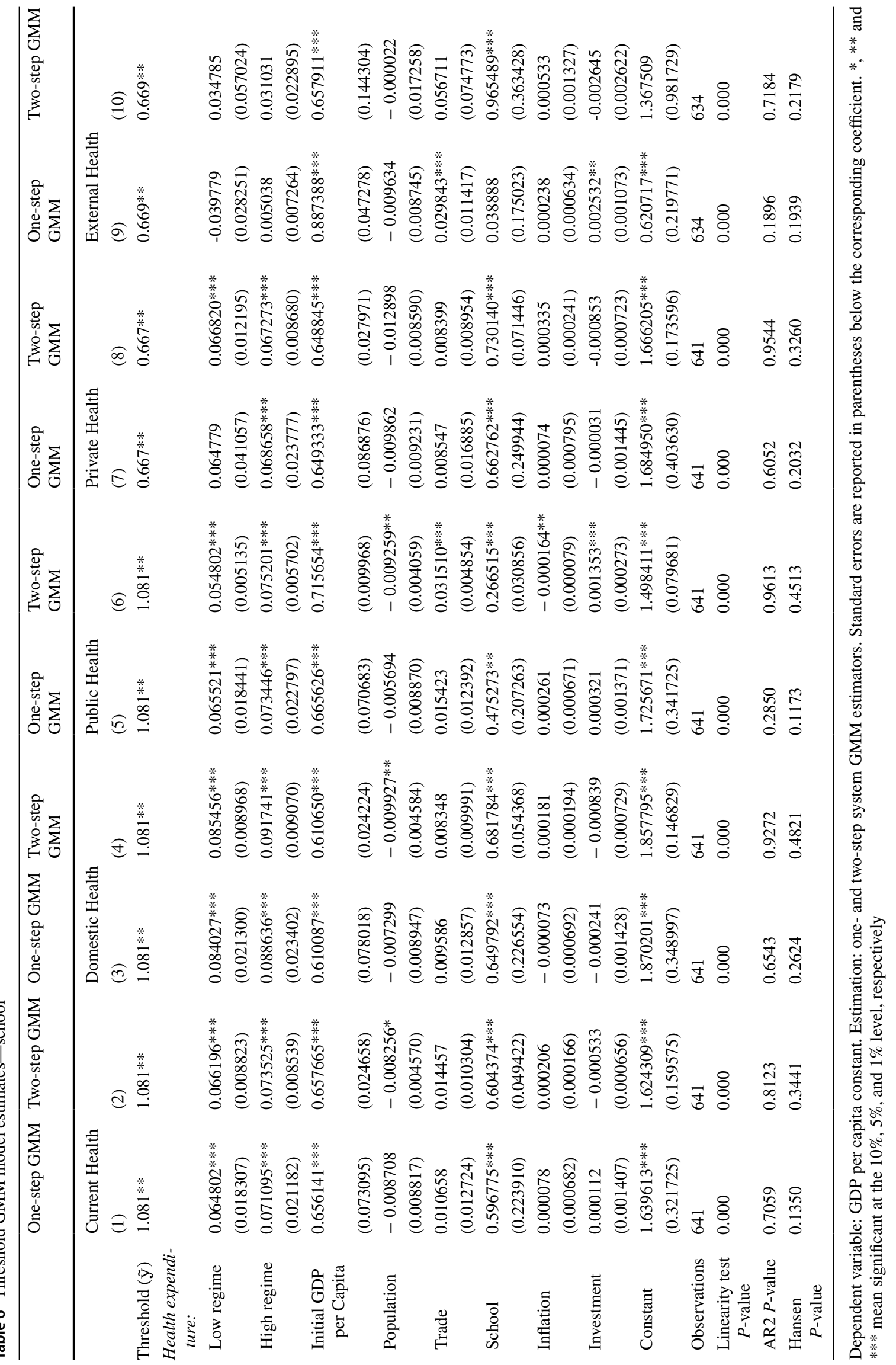




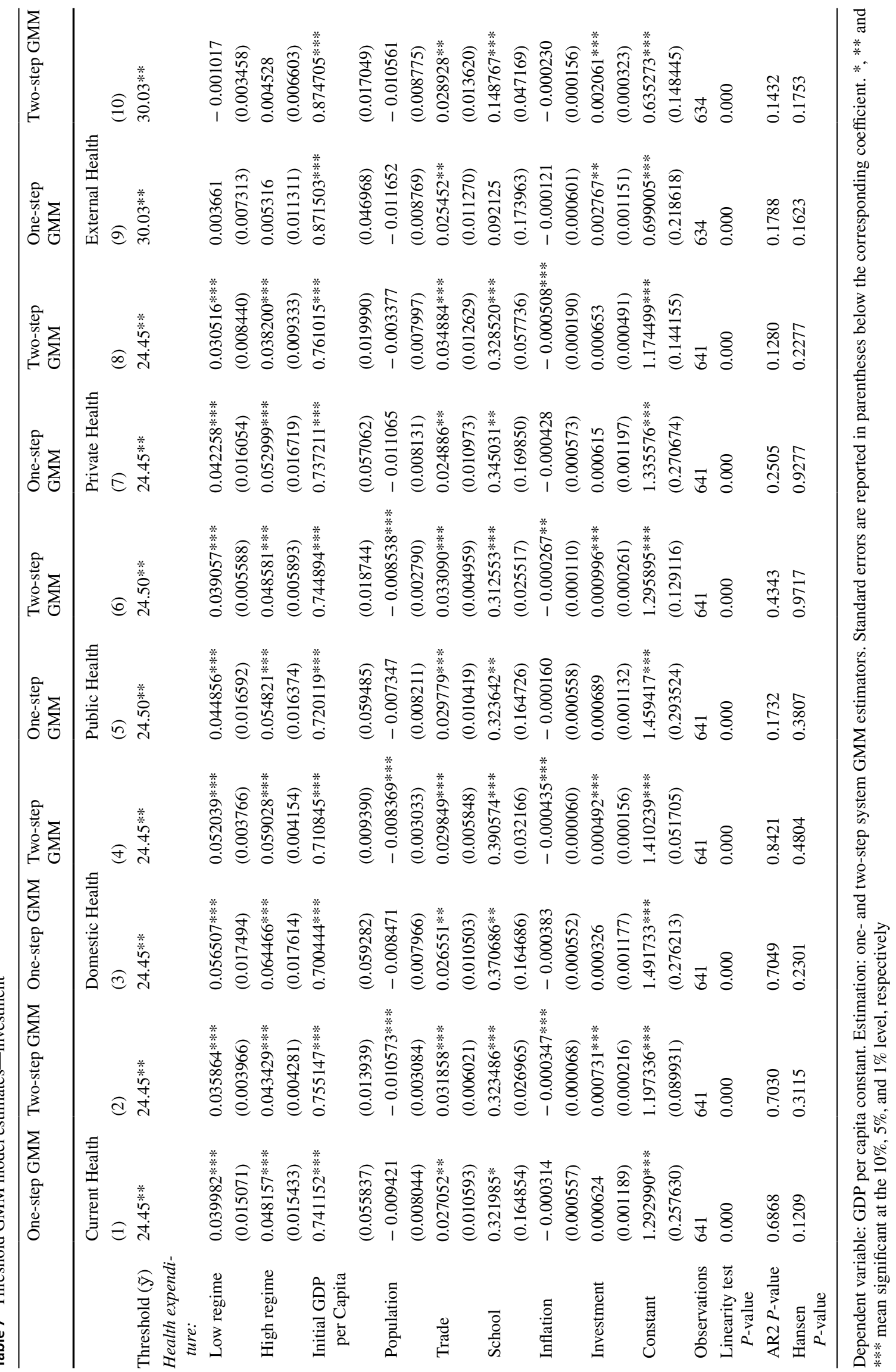


are consistent with the theoretical and empirical literature on endogenous growth. The coefficients confirm the positive impact of the level of education, investment, and trade openness on income growth. They also show that more inflation and population growth reduce income growth. The convergence term included in the coefficient of initial GDP per capita is also statistically significant at the $1 \%$ and $5 \%$ levels, confirming the relevance of our dynamic specification. Wald's linearity test indicates a significant non-linear relationship at the $1 \%$ level for all the regressions shown in Tables 6 and 7. In addition, the Hausman and AR2 tests show that these regressions are relatively well specified.

\section{Discussion}

This study reassesses the HLGH [9] for a large sample of developing countries. In line with Erdil and Yetkiner [26], Narayan et al. [14], Farag et al. [27], Piabuo and Tieguhong [24], Aboubacar and Xu [25], Rizvi [15], and Sarpong et al. [16], it argues that health spending is one of the most important determinants of economic development in these countries. The main findings reveal that domestic private and public health spending promotes economic growth in low- and middle-income economies, which contrasts with the study of Eggoh et al. [18] and De Mendonça and Baca [17] who show a negative impact of public health spending on growth and Halıc1-Tülüce et al. [10] who find that it is private spending that discourages growth. This implies that, despite their relatively low level of human and physical capital, developing economies can benefit from domestic private and public health spending, beyond the social and humanitarian relevance of such spending. The argument behind this could be the beneficial influence of health spending on population health and then on worker productivity, since good health workers are supposed to learn more quickly and easily and provide more productive labor time, thereby increasing aggregate output. We examine and validate this explanation by showing that domestic public and private health expenditure improves output per worker, thus providing empirical support for the arguments of endogenous growth theory (e.g., [4-6]). Another novel finding of the study is that an improvement in human and physical capital enhances the positive growth effect of domestic public and private health spending in developing countries, revealing complementarity rather than substitutability between health, physical and educational capital. In contrast to Yang [13] and Eggoh et al. [18] who argue that high education is a necessary condition for the HLGH, we provide evidence that it is a stimulus for the positive growth effect of domestic public and private health spending and that such spending does not compete with or undermine the beneficial effects of other human or physical capital spending. Somewhat similar conclusions have been drawn by Frimpong and Adu [28] and Sarpong et al. [16] for different samples of sub-Saharan African countries. Furthermore, while this study supports the HLGH [9] in developing countries for domestic public and private health spending, it qualifies it for external health spending. No significant impact of external care health expenditure on income growth is found for low and middle-low income countries, indicating that external transfers distributed by the government, which include all funds entering the national health system from abroad, do not really contribute to economic development in developing countries at the macro level. One reason of this result could be the low level of external health expenditure per capita (7.18 US dollars, see Appendix Table 9) compared to domestic health expenditure per capita (60.84 US dollars, see Appendix Table 9). Another explanation could be that external financing of health care increases external debt, which in turn decreases economic growth, as it is well documented that indebtedness is often counterproductive in developing economics [47]. In addition, institutional weakness in developing countries could lead to misallocation of external health funds, as the domestic spending strategy for these foreign resources is not systematically monitored by donors. For example, Lee et al. [40] argue that international health assistance for least developed countries may not necessarily keep pace with the economic needs of recipients. Finally, the World Health Organization report [48] indicates that in low-income economies, particularly African ones, the external source for health can reduce the proportion of public health spending 
in total health expenditure. In this respect, external health spending may not contribute to income growth in developing countries, as it undermines the positive effect of public health spending on economic growth.

\section{Conclusion and policy implications}

In September 2020, the world reached the psychological threshold of one million deaths due to the COVID-19 pandemic, indicating that the global health situation is not very reassuring. In this context, voices are being raised to assert that humanity has chosen health over economics, as budget deficits are increasing exponentially worldwide after health spending has reached unprecedented levels. Given the lack of resources that characterizes developing countries, the issue of the economic relevance-beyond the social and health necessity—of health spending, especially in terms of growth, arises.

In the face of the global sanitary crisis, this study reassessed the impact of different types of health expenditure on income growth on a large sample of 60 developing countries covering the most recent data available from 2000 to 2017. We developed an empirical dynamic panel data model of income growth based on an augmented endogenous growth model and we estimated it using dynamic linear and threshold GMM models to capture dynamic, linear, and non-linear effects. This allowed us to obtain consistent estimates corrected for endogeneity bias after controlling for the reversal causality and omitted variable problems that characterize the health-growth nexus.

The most important conclusion of our study is that public and private domestic health expenditure promotes income growth in developing countries and that the higher the levels of human and physical capital in these countries, the greater this virtuous effect. However, even in developing countries with relatively low levels of human and physical capital, private and public domestic health expenditures play a positive role in increasing per capita income levels, in addition to the social and humanitarian benefits. Such spending ensures better health of the population and thus better productivity of workers, thereby increasing aggregate output. Surprisingly, however, external health expenditure does not produce this effect. This means that developing countries do not really benefit from transfers from abroad allocated by the government to the national health system in terms of income growth, despite the important social and health role played by such external health expenditure. The low share of this expenditure in total current health expenditure and its inefficient allocation by national and international institutions may be at the root of this disappointing result. In addition, external health financing could increase the external debt of developing countries, jeopardizing income growth through higher debt payments and increased risk of default and crisis. Finally, external health spending could compete with and undermine the beneficial effects of domestic public health spending, as developing country governments may cut public health budgets when expecting external health aid.

The main recommendation that emerges from this study is that policy makers in developing countries must invest in health, invest in social protection and, most importantly, avoid austerity, which risks devastating both the health of many people and their incomes. Encouraging investment in health and social protection-especially when the economy is unstable-is a mark of responsible political action, both humanely and economically. International health aid must keep pace with the needs of beneficiaries not only in social and health terms, but also in economic development. This can be done by increasing the volume of these aids as well as the quality of their allocation. National governments should play a greater role in this regard by fighting corruption and improving the governance of public and private health institutions. In addition, there are more complex underlying challenges that require effective strategies and smart policies to protect population health and thereby stimulate worker productivity and income growth through national health spending in developing countries. This includes regulatory reforms to increase taxes on products that are harmful to health, such as taxes on cigarettes and sugar-sweetened beverages, to raise funds for the public health sector. These taxes are being implemented in developed and some emerging countries, but are even less widely adopted in developing 
countries. Governments should ensure that the winners of the COVID-19 pandemic, including technology companies, contribute to rebuilding the public health sector. A temporary health tax on profits made during the pandemic could be a source of public funding to support post-pandemic public health spending. Governments should also prioritize health spending in public financing plans and as part of the annual public budget, as it increases national income. To improve the management of public health expenditure, performance-based financing can be adopted as a measure to achieve predetermined targets with increased transparency and accountability. Such a measure could avoid misallocation of domestic and external health funds in developing countries. Improved data and information collection, including the creation of national databases, which will enhance and evaluate health spending, should also be implemented to strengthen performance-based financing measures. Given the complementarity between health, education and physical capital found in this study, far-reaching health education focusing on basic hygiene and sanitation should include in public policy formulations, and investments in health-promoting technologies should be encouraged by policymakers. Policymakers should build strong bridges between the financial authorities and the public and private health sectors to raise funds for domestic health expenditures. Improving the predictability of domestic and external health funds and

expenditures, taking into account the risk of future pandemics and health disasters, allows for greater efficiency and responsiveness of health programs. Far-reaching institutional reforms to create a specialized entity with a business intelligence mandate, clear institutional responsibilities, and the authority to formulate, implement, evaluate and report on ongoing programs should be implemented.

Based on this study, several directions for future research emerge. The unavailability of developing country health expenditure data covering the COVID-19 period is a limitation of this study. Future studies can replicate this analysis by incorporating this time period to draw new conclusions regarding the HLGH. Using the dynamic threshold GMM model developed in this study, future research can examine the impact of external health expenditure on economic growth by considering different external debt thresholds in developing countries. This model could also allow future analyses to explore whether there is complementarity or substantiality between different types of health expenditures (domestic, external, public, private, etc.) in their impact on income growth in developing countries.

\section{Appendix}

Table 8 Variables, definition and sources

\begin{tabular}{lll}
\hline Variables & Definition & Sources \\
\hline Current Health & $\begin{array}{l}\text { Current expenditure on health (goods and services consumed) per capita in US } \\
\text { dollars }\end{array}$ & World Development Indicators World Bank \\
Domestic Health & $\begin{array}{l}\text { Current domestic expenditure on health (current expenditure-external } \\
\text { expenditure) per capita in US dollars }\end{array}$ & World Development Indicators World Bank \\
Public Health & $\begin{array}{l}\text { Current public expenditure on health per capita in US dollars } \\
\text { Private Health }\end{array}$ & $\begin{array}{l}\text { Current private expenditure on health per capita in US dollars } \\
\text { External Health }\end{array}$ \\
& $\begin{array}{l}\text { Current external expenditure on health (financial inflows) per capita in US } \\
\text { dollars }\end{array}$ & World Development Indicators World Bank \\
GDP per Capita & GDP per capita constant in in US dollars & World Development Indicators World Bank \\
Output per Worker & GDP constant/Labor force & World Development Indicators World Bank \\
Population & Population growth (annual \%) & World Development Indicators World Bank \\
Trade & The sum of exports and imports (\% of GDP) & World Development Indicators World Bank \\
School & School enrollment, primary and secondary (gross), gender parity index (GPI) & World Development Indicators World Bank \\
Inflation & Inflation, consumer prices (annual \%) & World Development Indicators World Bank \\
Investment & Gross capital formation (\% of GDP) & World Development Indicators World Bank \\
\hline
\end{tabular}




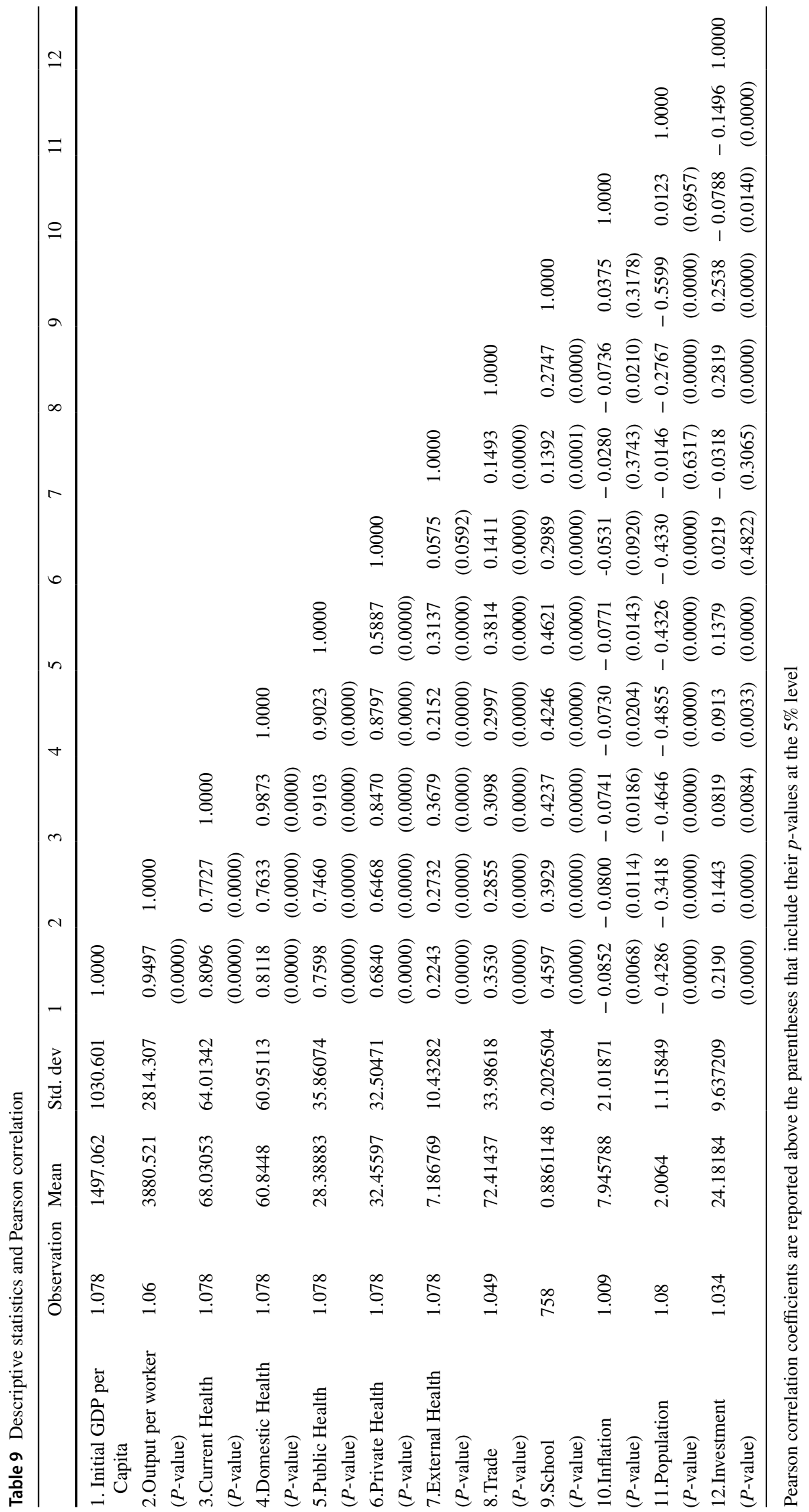



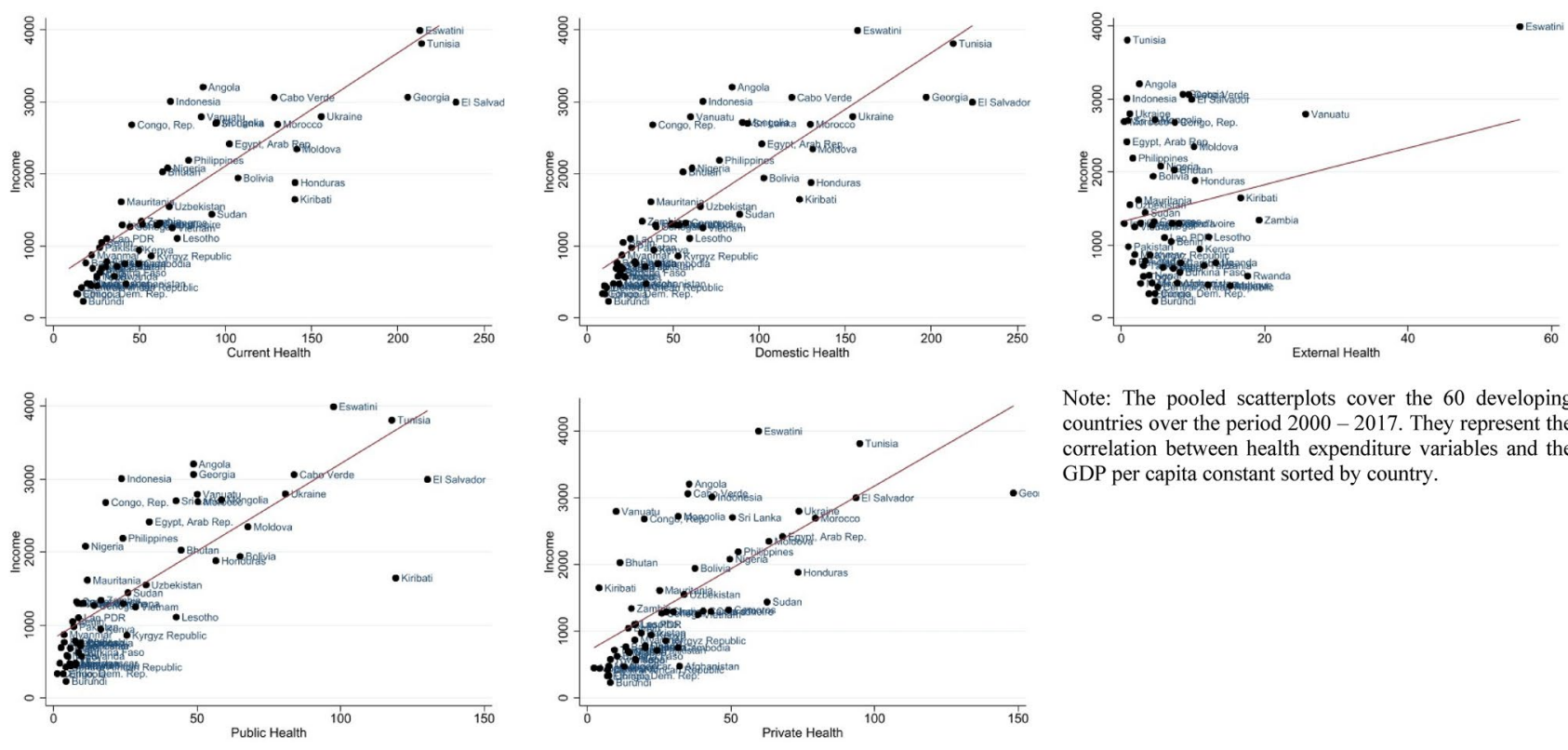

Note: The pooled scatterplots cover the 60 developing countries over the period $2000-2017$. They represent the correlation between health expenditure variables and the GDP per capita constant sorted by country.

Fig. 1 Health expenditure and income by country

\section{List of countries:}

Low-middle-income developing countries (60): Afghanistan Angola Bangladesh Benin Bhutan Bolivia Burkina Faso Burundi Cabo Verde Cambodia Cameroon Central African Republic Chad Comoros Congo, Dem. Rep. Congo, Rep. Cote d'Ivoire Egypt, Arab Rep. El Salvador Eswatini Ethiopia Georgia Ghana Guinea Honduras India Indonesia Kenya Kiribati Kyrgyz Republic Lao PDR Lesotho Madagascar Malawi Mali Mauritania Moldova Mongolia Morocco Mozambique Myanmar Nepal Niger Nigeria Pakistan Philippines Rwanda Senegal Sri Lanka Sudan Tajikistan Tanzania Togo Tunisia Uganda Ukraine Uzbekistan Vanuatu Vietnam Zambia. Low-income countries (22): Afghanistan Benin Burkina Faso Burundi Central African Republic Chad Comoros Congo, Dem. Rep. Ethiopia Guinea Madagascar Malawi Mali Mozambique Nepal Niger Rwanda Senegal Tajikistan Tanzania Togo Uganda. Lower-middle-income countries (38): Angola Bangladesh Bhutan Bolivia Cabo Verde Cambodia Cameroon Congo, Rep. Cote d'Ivoire Egypt, Arab Rep. El Salvador Eswatini Georgia Ghana Honduras India Indonesia Kenya Kiribati Kyrgyz Republic Lao PDR Lesotho Mauritania Moldova Mongolia Morocco Myanmar Nigeria Pakistan Philippines Sri Lanka Sudan Tunisia Ukraine Uzbekistan Vanuatu Vietnam Zambia

\section{References}

1. Deb, P., Furceri, D., Ostry, J.D., Tawk, N.: The effect of containment measures on the COVID-19 pandemic. Covid Econ. Vetted Real-Time Pap. 19, 53-86 (2020)

2. UNCTAD: From the great lockdown to the great meltdown: Developing country debt in the time of Covid-19. Trade and Development Report Update. Geneva (2020)

3. Stubbs, T., Kring, W., Laskaridis, C., Kentikelenis, A., Gallagher, K.: Whatever it takes? The global financial safety net, Covid-19, and developing countries. World Dev. 137, 105-171 (2020)

4. Grossman, G.M., Helpman, E.: Trade, knowledge spillovers, and growth. Eur. Econ. Rev. 35(2-3), 517-526 (1991)

5. Mankiw, N.G., Romer, D., Weil, D.N.: A contribution to the empirics of economic growth. Q. J. Econ. 107(2), 407-437 (1992)

6. Aghion, P., Howitt, P.: Research and development in the growth process. J. Econ. Growth 1(1), 49-73 (1996)

7. Bloom, D.E., Canning, D., Sevilla, J.: Health and economic growth: Reconciling the micro and macro evidence. DDRL. Stanford Working Paper 42 (2005)

8. Amiri, A., Ventelou, B.: Granger causality between total expenditure on health and GDP in OECD: evidence from the Toda-Yamamoto approach. Econ. Lett. 116(3), 541-544 (2012)

9. Atilgan, E., Kilic, D., Ertugrul, H.M.: The dynamic relationship between health expenditure and economic growth: is the healthled growth hypothesis valid for Turkey? Eur. J. Health Econ. 18(5), 567-574 (2017)

10. Halıc1-Tülüce, N.S., Doğan, İ, Dumrul, C.: Is income relevant for health expenditure and economic growth nexus? Int. J. Health Econ. Manag. 16(1), 23-49 (2016)

11. Baltagi, B.H., Moscone, F.: Health care expenditure and income in the OECD reconsidered: evidence from panel data. Econ. Model. 27(4), 804-811 (2010) 
12. Naidu, S., Chand, A.: Does central government health expenditure and medical technology advancement determine economic growth rates in the Pacific island countries? Asia Pac. J. Bus. Adm. 5(3), 234-245 (2013)

13. Yang, X.: Health expenditure, human capital, and economic growth: an empirical study of developing countries. Int. J. Health Econ. Manag. 1-14 (2020)

14. Narayan, S., Narayan, P.K., Mishra, S.: Investigating the relationship between health and economic growth: empirical evidence from a panel of 5 Asian countries. J. Asian Econ. 21(4), 404-411 (2010)

15. Rizvi, S.A.F.: Health expenditures, institutional quality and economic growth. Empir. Econ. Rev. 2(1), 63-82 (2019)

16. Sarpong, B., Nketiah-Amponsah, E., Owoo, N.S.: Health and economic growth nexus: evidence from selected sub-Saharan African (SSA) countries. Glob. Bus. Rev. 21(2), 328-347 (2020)

17. De Mendonça, H.F., Baca, A.C.: Relevance of corruption on the effect of public health expenditure and taxation on economic growth. Appl. Econ. Lett. 25(12), 876-881 (2018)

18. Eggoh, J., Houeninvo, H., Sossou, G.A.: Education, health and economic growth in African countries. J. Econ. Dev. 40(1), 93 (2015)

19. Hansen, B.E.: Threshold effects in non-dynamic panels: estimation, testing, and inference. J. Econ. 93(2), 345-368 (1999)

20. Ullah, S., Akhtar, P., Zaefarian, G.: Dealing with endogeneity bias: the generalized method of moments (GMM) for panel data. Ind. Mark. Manag. 71, 69-78 (2018)

21. Bond, S.R.: Dynamic panel data models: a guide to micro data methods and practice. Port. Econ. J. 1(2), 141-162 (2002)

22. Beck, N., Katz, J.N.: Modeling dynamics in time-series-crosssection political economy data. Annu. Rev. Polit. Sci. 14, 331-352 (2011)

23. Seo, M.H., Shin, Y.: Dynamic panels with threshold effect and endogeneity. J. Econ. 195(2), 169-186 (2016)

24. Piabuo, S.M., Tieguhong, J.C.: Health expenditure and economic growth- a review of the literature and an analysis of the economic community for central African states (CEMAC) and selected African countries. Health Econ Rev (2017). https://doi.org/10.1186/ s13561-017-0159-1

25. Aboubacar, B., Xu, D.: The impact of health expenditure on the economic growth in Sub- Saharan Africa. Theor. Econ. Lett. 7(03), 615 (2017)

26. Erdil, E., Yetkiner, I.H.: The Granger-causality between health care expenditure and output: a panel data approach. Appl. Econ. 41(4), 511-518 (2009)

27. Farag, M., Nanda Kumar, A.K., Wallack, S., Hodgkin, D., Gaumer, G., Erbil, C.: The income elasticity of health care spending in developing and developed countries. Int. J. Health Care Financ. Econ. 12(2), 145-162 (2012)

28. Frimpong, P.B., Adu, G.: Population health and economic growth in Sub-Saharan Africa: a panel cointegration analysis. J. Afr. Bus. 15(1), 36-48 (2014)

29. Pesaran, M.H., Shin, Y., Smith, R.P.: Pooled mean group estimation of dynamic heterogeneous panels. J. Am. Stat. Assoc. 94(446), 621-634 (1999)

30. Darku, A.B., Yeboah, R.: Economic openness and income growth in developing countries: a regional comparative analysis. Appl. Econ. 50(8), 855-869 (2018)
31. David, O.O.: Powering economic growth and development in Africa: telecommunication operations. Appl. Econ. 51(33), 3583-3607 (2019)

32. Roodman, D.: xtabond2: stata module to extend xtabond dynamic panel data estimator (2018)

33. Gaies, B., Goutte, S., Guesmi, K.: What interactions between financial globalization and instability? - growth in developing countries. J. Int. Dev. 31(1), 39-79 (2019)

34. Gaies, B., Goutte, S., Guesmi, K.: Does financial globalization still spur growth in emerging and developing countries? Considering exchange rates. Res. Int. Bus. Financ. 52, 101-113 (2020)

35. Arellano, M., Bond, S.: Some tests of specification for panel data: Monte Carlo evidence and an application to employment equations. Rev. Econ. Stud. 58(2), 277-297 (1991)

36. Arellano, M., Bover, O.: Another look at the instrumental variable estimation of error-components models. J. Econ. 68(1), 29-51 (1995)

37. Blundell, R., Bond, S.: Initial conditions and moment restrictions in dynamic panel data models. J. Econ. 87(1), 115-143 (1998)

38. Windmeijer, F.: A finite sample correction for the variance of linear efficient two-step GMM estimators. J. Econ. 126(1), 25-51 (2005)

39. Windmeijer, F., Liang, X., Hartwig, F. P., Bowden, J.: The confidence interval method for selecting valid instrumental variables (No. 19/715). Department of Economics, University of Bristol (2019)

40. Lee, S.A., Lim, J.Y.: Does international health aid follow recipients' needs? Extensive and intensive margins of health aid allocation. World Dev. 64, 104-120 (2014)

41. Diallo, I.: XTENDOTHRESDPD: Stata module to estimate a dynamic panel data threshold effects model with endogenous regressors. Statistical software components S458745, Boston College Department of Economics, Accessed date 18 Apr 2020 (2020)

42. Caliendo, F.N., Findley, T.S.: Myopia, education, and social security. International Tax and Public Finance 1-27 (2019)

43. Zhang, M., Zou, X., Sha, L.: Social security and sustainable economic growth: based on the perspective of human capital. Sustainability 11(3), 662 (2019)

44. Kremer, S., Bick, A., Nautz, D.: Inflation and growth: new evidence from a dynamic panel threshold analysis. Empir. Econ. 44(2), 861-878 (2013)

45. Zhu, X., Asimakopoulos, S., Kim, J.: Financial development and innovation-led growth: is too much finance better? J. Int. Money Financ. 100, 102083 (2020)

46. Osei, M.J., Kim, J.: Foreign direct investment and economic growth: is more financial development better? Econ. Model. 93, 154-161 (2020)

47. Gaies, B., Nabi, M. S.: Banking crises and economic growth in developing countries: Why privileging foreign direct investment over external debt?. Bull. Econ. Res. (2021)

48. World health statistics: Monitoring health for the SDGs, sustainable development goals. World Health Organization, Geneva (2018)

Publisher's Note Springer Nature remains neutral with regard to jurisdictional claims in published maps and institutional affiliations. 